\title{
Estrategias comunicativas en Twitter y portales institucionales durante la segunda ola de Covid-19: análisis de los gobiernos de Alemania, España, Portugal y Reino Unido
}

\section{Communication strategies on Twitter and institutional websites in the Covid-19 second wave: analysis of the governments of Germany, Spain, Portugal and the United Kingdom}

Rubén Rivas-de-Roca. Universidad de Sevilla. España.

rrivasderoca@us.es

$[\mathrm{CV}]$ (1) $\mathrm{R}: 0$

Mar García-Gordillo. Universidad de Sevilla. España.

marggordillo@us.es

\section{$[\mathrm{CV}]$ (1) $\mathrm{R}$ i 0}

José Luis Rojas-'Torrijos. Universidad de Sevilla. España.

jlrojas@us.es

$[\mathrm{CV}]$ (1) $\mathrm{G}$

Este trabajo ha sido financiado por el VI PPIT-US (Plan Propio de Investigación y Transferencia de la Universidad de Sevilla), mediante el Contrato Predoctoral para el Desarrollo del Programa Propio I+D $+i$ de la US en Áreas de Especial Atención asignado al Departamento de Periodismo II (2017), que tiene como beneficiario al autor Rubén Rivas-de-Roca. Inicio de la investigación: 01/10/2020. Término de la investigación: 31/01/2021.

Cómo citar este artículo / Referencia normalizada

Rivas-de-Roca, R., García-Gordillo, M. y Rojas-Torrijos, J. L. (2021). Estrategias comunicativas en Twitter y portales institucionales durante la segunda ola de Covid-19: análisis de los gobiernos de Alemania, España, Portugal y Reino Unido. Revista Latina de Comunicación Social, 79, 4973. https://www.doi.org/10.4185/RLCS-2021-1517

\section{RESUMEN}

Introducción: Las restricciones sociales impuestas por la pandemia de Covid-19 acentuaron el rol de las tecnologías como herramientas de interacción, pero también la función de las mismas en la comunicación institucional desarrollada por los gobiernos para explicar sus decisiones políticas ante una situación de crisis. Metodología: Esta investigación analiza comparativamente algunas de las estrategias comunicativas de los gobiernos de Alemania, España, Portugal y Reino Unido. Para ello se estudian los temas y objetivos de sus líderes o portavoces en Twitter: Steffen Seibert como representante de Merkel (Alemania), Pedro Sánchez (España), António Costa (Portugal) y Boris Johnson (Reino Unido). Asimismo, se analizan los mensajes en las webs oficiales de los gobiernos (Bundesregierung, La Moncloa, República Portuguesa y GOV.UK). Resultados: Se advierte una 
infrautilización de las potencialidades interactivas. Además, los temas y objetivos preferentes se repiten en Twitter y los portales institucionales, centrándose en el anuncio y evaluación de cuestiones sanitarias y económicas, si bien los mensajes en la red social abordan una mayor pluralidad de asuntos que no coindicen con los más retuiteados. Discusión: Las similitudes y divergencias halladas plantean una reflexión sobre el papel de las culturas políticas en la intervención comunicativa de los gobiernos, así como acerca de la necesidad de responder a los intereses de la audiencia. Conclusiones: La comunicación gubernamental se ha dirigido a las cuestiones más inmediatas de la pandemia, como la sanidad y la economía, desarrollando una agenda más amplia en Twitter que, en cambio, no se corresponde con los intereses observados entre el público.

PALABRAS CLAVE: Comunicación de crisis; comunicación institucional; comunicación política; Covid-19; liderazgo; portales institucionales; Twitter.

\begin{abstract}
Introduction: The social restrictions imposed by the Covid-19 pandemic increased the role of digital technologies as tools of interaction, but also their role in the institutional communication developed by governments to explain their political decisions in a crisis situation. Methodology: This study examines some of the communication strategies of the governments of Germany, Spain, Portugal and the United Kingdom. To do this, the topics and objectives of their leaders or spokespersons on Twitter are studied: Steffen Seibert representing Merkel (Germany), Pedro Sánchez (Spain), António Costa (Portugal), and Boris Johnson (United Kingdom). Likewise, the messages disseminated on the official websites of the governments (Bundesregierung, La Moncloa, República Portuguesa and $G O V . U K)$ are analyzed. Results: Results show a low use of digital interaction potential. In addition, the preferred themes and objectives are repeated on Twitter and institutional webs, focusing on the announcement and evaluation of health and economic issues. However, the messages on the social network refer to a greater plurality of issues. Discussion: Based on the similarities and divergences found, we argue that a reflection on the role of political cultures in communication actions should be noted, as well as the need to respond to the interests of the audience. Conclusions: Government communication has addressed the most immediate issues of the pandemic, such as health and the economy, developing a broader agenda on Twitter that, on the other hand, did not correspond to the interests observed among the public.
\end{abstract}

KEYWORDS: Crisis communication; Covid-19; institutional communication; institutional webs; leadership; political communication; Twitter.

\title{
CONTENIDO
}

1. Introducción. 2. Antecedentes. 2.1. Estrategias y comunicación política en Twitter. 2.2. Comunicación institucional en tiempos de crisis: el rol de las webs gubernamentales. 3. Metodología. 4. Resultados. 4.1. Descripción de la muestra y análisis cualitativo. 4.2. Temáticas y objetivos de la comunicación gubernamental. 4.3. Fuentes informativas e intereses de los ciudadanos. 5. Discusión y conclusiones. 6. Referencias.

\section{Introducción}

Las tecnologías digitales suponen una pieza fundamental en la actual comunicación política, que altera el ciclo tradicional de la información hacia un nuevo rol de la audiencia (Enli, 2017). La pandemia de la Covid-19 ha incrementado el peso de la digitalización como forma de llegar a la ciudadanía, ante un conjunto de restricciones sociales en las distintas olas víricas. Los gobiernos han tenido que recurrir a espacios como las redes sociales para explicar sus decisiones y validar así sus acciones (Losada Díaz et al., 2020). Las investigaciones acerca de la primera ola pandémica señalan 
una creciente personalización de la comunicación política en distintos contextos geográficos (Manfredi-Sánchez et al., 2021).

Si bien la llegada del virus en la primavera de 2020 fue un suceso inesperado, la gestión posterior permite la observación de tendencias en la comunicación pública institucional. Su desarrollo se produce en un entorno híbrido, en el que los sistemas tradicionales y digitales conviven para la configuración de la esfera pública (Chadwick, 2017). De hecho, la Covid-19 ha significado un nuevo protagonismo de los medios convencionales como vía de información ciudadana, al erigirse en una fuente confiable (Casero-Ripollés y García-Gordillo, 2021). Por tanto, los hallazgos acerca de cómo se articula la conversación política son ambivalentes, aunque se constata la influencia de las redes sociales en el sistema mediático tradicional (Broersma y Graham, 2013; Hermida y Mellado, 2020).

La personalización espoleada por el uso político de las redes sociales no ha generado el grado de interacción esperado con la audiencia, reproduciendo el modelo de comunicación unidireccional (Boerman y Kruikemeier, 2016). Esto lastra la participación ciudadana, clave en la construcción de un idealizado espacio digital de intercambio entre gobernantes y gobernados (Sampedro y Martínez Avidad, 2018). Otro elemento perjudicial en su génesis ha sido la enorme proliferación de la desinformación en los últimos años (Bimber y Gil de Zúñiga, 2020), alimentando la desconfianza y el cinismo hacia la clase política.

En este sentido, la Covid-19 trajo consigo un fenómeno de "infodemia" (Nielsen et al., 2020), marcado por la aparición de bulos y falsas creencias, que podía incrementar aún más el desprestigio de unas autoridades responsables de la actuación sanitaria. Esto conecta con los efectos nocivos de la desinformación en el incremento del descrédito de las instituciones públicas, muy tangible en una situación de pandemia que implica una amplia actuación gubernamental (Pérez-Curiel y Velasco Molpeceres, 2020). Hay que tener en cuenta que el impacto de la desinformación, así como el uso de redes sociales, varía por países (Fletcher et al., 2020), haciendo necesarios estudios comparados que permitan conocer la respuesta comunicativa a la pandemia de distintos gobiernos.

Esta investigación contribuye al estado de la materia analizando herramientas de comunicación institucional implementadas por los gobiernos de Alemania, España, Portugal y Reino Unido para la gestión de la Covid-19, adscritos a diferentes culturas políticas y mediáticas (Hanusch y Hanitzsch, 2017). Las cuentas personales en Twitter de los responsables políticos son de interés, pero también las webs institucionales, en tanto que funcionan como fuente de información para los medios y ciudadanos (Bruns et al., 2016). Se busca de esta manera explorar los temas, objetivos y recursos empleados en una situación de crisis asentada.

\section{Antecedentes}

\subsection{Estrategias y comunicación política en Twitter}

La red social Twitter ha acaparado en la última década una gran atención como herramienta de comunicación para los emisores políticos, ya sean líderes u organizaciones sociales (Aharony, 2012; Campos-Domínguez, 2017). Sus rasgos de instantaneidad se adaptan al ritmo acelerado de la información (Gainous y Wagner, 2014), lo que la convierte en un canal privilegiado de la comunicación política (Jungherr, 2016). Parte del éxito de Twitter en este ámbito radica en que permite un flujo informativo directo desde la clase dirigente hacia la ciudadanía, algo que se reveló fundamental en la estrategia institucional ante la irrupción de la Covid-19 (Drylie-Carey et al., 2020). 
Twitter redunda en una tendencia asentada como es la personalización de la política (McAllister, 2007), al brindar espacio a cuestiones más humanas que imbrican con el infoentretenimiento y la política pop (Crilley y Gillespie, 2019; Kruikemeier et al., 2013). Sin embargo, las posibilidades comunicativas de este canal directo quedan reducidas por la interactividad limitada que caracteriza la acción en Twitter de los actores políticos (Stromer-Galley, 2014). Frente a ello, su principal misión es la difusión de información, una práctica que encaja con las necesidades de datos durante la pandemia y que hasta ahora había sido principalmente empleada en períodos electorales (D'Heer y Verdegem, 2015).

El papel de Twitter en fenómenos de desinformación que han aupado a formaciones y figuras populistas en todo el mundo puede provocar una desconfianza en el sistema político (Engesser et al., 2017). La literatura apunta a que el populismo utiliza las redes sociales para difundir su ideología de manera fragmentada, presentándose como oposición al establishment (van Kessel y Castelein, 2016). El impacto democrático de estas plataformas se articula en objeto de preocupación académica (Bennett y Livingstone, 2018), que a su vez evidencia las dificultades para ser interpretadas como fuentes confiables por parte de la ciudadanía.

Más allá de que el uso de Twitter con fines políticos difiere enormemente por países (Scherpereel et al., 2016), la pandemia abre la puerta a un redescubrimiento de las potencialidades de las redes sociales, ampliamente abordadas como lugares de emisión y escasa interactividad (Geise et al., 2021). La Covid19 ha acelerado los cambios en los patrones de consumo, de ahí que pueda haber espacio para aproximaciones más visuales y dinámicas de Twitter que entronquen con los mecanismos de transparencia demandados por la sociedad.

\subsection{Comunicación institucional en tiempos de crisis: el rol de las webs gubernamentales}

La comunicación institucional cumple una función social de carácter democrático desde sus orígenes (Rebolledo et al., 2017). No obstante, en situaciones de crisis este rasgo adquiere un significado especial, ya que es fundamental como herramienta de comunicación entre las instituciones públicas y sus gobernados para reducir la incertidumbre social que genera la nueva situación y mitigar su impacto (Cornelissen, 2008; Sierra Rodríguez, 2020).

La coordinación de la comunicación gubernamental en estas situaciones debe estar posicionada en la cúspide de la pirámide de la toma de decisiones (Jacobs y Wonneberger, 2019). El diseño de una estrategia de comunicación para la gestión de la crisis, la elaboración de mensajes claros, directos e inequívocos para cada uno de los medios y soportes (Burgueño, 2014), las campañas de concienciación y educación social dirigidas a los distintos targets de audiencias, la transparencia (Díez Garrido et al., 2019), la escucha activa, las comparecencias, etc., son claves comunicativas fundamentales para la gestión de crisis por parte de las instituciones públicas.

La coyuntura actual provocada por la COVID-19 ha hecho que la comunicación se revele como una herramienta esencial para la gestión de la crisis auspiciada por la pandemia. Los gobiernos han tenido que diversificar sus estrategias comunicativas para adaptarlas no solo atendiendo a los medios de comunicación tradicionales (Barroso Simao et al., 2016), que han visto alterado su monopolio del mensaje informativo (Langer y Gruber, 2021), sino también elaborando información para herramientas como las webs y las redes sociales, que permiten alcanzar al ciudadano sin mediación alguna (Kreiss y McGregor, 2018). También necesitan de un dominio de códigos comunicativos nuevos y diversos para cada uno de ellos, obligan a mantener una actitud activa de escucha y respuesta al ciudadano, y exigen un seguimiento y control del mensaje para gestionar bulos y fake news (Bennett y Livingstone, 2018), que pueden propiciar otras crisis que van más allá de la sanitaria. 
Las webs gubernamentales constituyen una poderosa herramienta de comunicación, una ventana abierta para la información del ciudadano que sirve de soporte para la gestión de otros canales comunicativos (Castillo-Esparcia et al., 2020). Los portales web deben ser el lugar donde los gobiernos se expresan en primera persona, publican sus decisiones y dan instrucciones a los distintos actores sociales (Hancu-Budui et al., 2020). En ellos se transmite información esencial para la ciudadanía, haciendo explícita la estrategia política, en términos generales y para la gestión de crisis específicas como la pandemia de Covid-19.

A la vista de lo anterior, este estudio tiene como objetivo principal analizar las estrategias comunicativas digitales de los gobiernos de Alemania, España, Portugal y Reino Unido ante la segunda ola de Covid-19 en otoño de 2020, en aras de valorar su uso de las plataformas tecnológicas en la rendición de cuentas democrática. De este planteamiento general se desgajan los siguientes objetivos:

O1. Analizar la configuración del lenguaje político implementado en dos canales comunicativos (Twitter y webs), observando posibles similitudes y divergencias.

$\mathrm{O} 2$. Conocer los temas (issues) y las finalidades que han centrado la comunicación gubernamental, tanto de figuras que asumen un rol de liderazgo como de las webs institucionales.

O3. Valorar una posible asimilación entre los mensajes institucionales y los intereses de la ciudadanía mediante el grado de interacción en Twitter.

\section{Metodología}

Esta investigación compara la gestión comunicativa efectuada por distintos gobiernos europeos, que articulan sus estrategias a través incluso de diferentes categorías de personalidades. Para ello, se propone responder a tres preguntas de investigación:

PI.1. ¿Se estructuran los mensajes digitales en torno a los mismos temas, objetivos y componentes discursivos por países?

PI.2. ¿Existen adaptaciones de la estrategia en función de la herramienta comunicativa seleccionada?

PI.3. ¿Se produce una correspondencia entre el contenido difundido y los intereses de la ciudadanía tras meses de experiencia en la gestión de la crisis?

Se aboga por la triangulación metodológica para abordar los objetivos fijados, empleando un análisis de contenido cuantitativo y cualitativo-discursivo (Callejo, 2010; Rivas-de-Roca et al., 2020). Aplicamos un protocolo multimétodo, que alude al estudio de los tweets de los líderes, las publicaciones en las webs institucionales y las métricas de interacción de los usuarios. Este enfoque se fundamenta en la necesidad de profundizar en un modelo mediático híbrido (Chadwick, 2017), en el que, sin embargo, las plataformas tecnológicas tienen cada vez un mayor peso en la configuración de la comunicación política (Kreiss y Mcgregor, 2018).

Para el estudio cuantitativo se utiliza el análisis de contenido, que posibilita detallar los elementos integrantes de un mensaje comunicativo (Krippendorff, 2012). La validez de esta modalidad en la investigación sobre Twitter ha sido avalada por diversas investigaciones (Brantner y Pfeffer, 2018; Fernández Crespo, 2014). En cuanto a la fase cualitativa, se lleva a cabo un estudio discursivo de contextualización (van Dijk, 2015), para el cual se acota una muestra basada en palabras claves obtenidas de manera inductiva del conjunto de piezas analizadas.

Se diseña una propuesta metodológica que analiza los perfiles en Twitter de los líderes o portavoces gubernamentales de Alemania, España, Portugal y Reino Unido. Se trata de países europeos pertenecientes a diferentes sistemas mediáticos (Hallin y Mancini, 2004) y culturas periodísticas 
derivadas de su tradición política (Hanusch y Hanitzsch, 2017), lo que genera diversas expectativas de interacción en sus audiencias digitales. Su selección también se explica porque se vieron fuertemente afectados por la segunda ola, en comparación con otros Estados como Italia y Francia, que sufrieron más la primera y la tercera onda vírica, respectivamente. El enfoque en esta red social se encuentra motivado por sus ventajas para la comunicación política e institucional (Bruns et al., 2016; D'Heer y Verdegem, 2015), siendo capaz de provocar cambios en el conocimiento democrático de la ciudadanía. Teniendo en cuenta sus potenciales implicaciones, se expone a continuación la muestra de perfiles en Twitter:

- Steffen Seibert (portavoz federal, Alemania). @ RegSprecher (cuenta única en alemán).

- Pedro Sánchez (presidente, España). @ sanchezcastejon (cuenta única en español).

- António Costa (primer ministro, Portugal). @ antoniocostapm (cuenta única en portugués).

- Boris Johnson (primer ministro, Reino Unido). @ BorisJohnson (cuenta única en inglés).

En el caso alemán, se selecciona a su portavoz federal porque Merkel no posee perfil en Twitter. Se da la circunstancia de que Seibert goza de una función de liderazgo en esta red social, contando con más de un millón de seguidores en su cuenta oficial de portavocía del gobierno germano (@RegSprecher). Este rol como canalizador de la comunicación de la cancillería se antoja útil para el presente estudio, aunque no constituya un jefe de Gobierno.

Además de los temas y los propósitos aparentes de los tweets institucionales, nuestro análisis contempla las páginas gubernamentales, ya que han jugado un papel en la difusión de información oficial en la crisis del coronavirus (Castillo-Esparcia et al., 2020). A ello se suma que los estudios previos sobre la comunicación en la pandemia han estado centrados en figuras individuales (Manfredi-Sánchez et al., 2021), dejando de lado la función de las webs institucionales como espacios de transparencia (Díez Garrido et al., 2019). Esto motiva la selección de los portales oficiales para cada país de la muestra:

- Bundesregierung (Alemania). https://www.bundesregierung.de/

- La Moncloa (España). https://www.lamoncloa.gob.es/

- República Portuguesa (Portugal). https://www.portugal.gov.pt/

- GOV.UK (Reino Unido). https://www.gov.uk/

Para evaluar las estrategias comunicativas se establece un período de recogida de datos que abarca del 1 de octubre al 31 de diciembre de 2020, una franja de tres meses en el que los países europeos tuvieron que adoptar nuevas restricciones para hacer frente a la segunda ola de Covid-19. La fecha final coincide con el cierre del año 2020, un potencial punto de inflexión hacia otras medidas en 2021. La comunicación política en Twitter ha sido intensamente analizada en procesos electorales (Gainous y Wagner, 2014; Jungherr, 2016), algo que se ha repetido en momentos de fuerte carga simbólica como la irrupción del coronavirus en la primavera de 2020 (Wang et al., 2021). En cambio, en situaciones valle, como la consolidación de pandemia a medio plazo, su uso resulta menos referenciado.

La muestra se compone de todos los tweets publicados por los perfiles mencionados, así como las publicaciones web acerca de la Covid-19, con objeto de delimitar la información escogida dentro de la gran proliferación comunicativa de los portales institucionales. Se efectúa una búsqueda en ellos basada en cuatro palabras clave: "Covid-19", "coronavirus", "pandemia" y "restricciones". Pretendemos conocer la interacción entre actores públicos y ciudadanos en los espacios digitales de la democracia, que la literatura identifica como progresivamente más endogámica y asimétrica, de acuerdo al fenómeno de plataformización (Colleoni et al., 2014; Smyrnaios y Rebillard, 2019). Esta es la razón por la cual la ficha cuantitativa/cualitativa (tabla 1) incorpora elementos discursivos al análisis de la temática y los objetivos (finalidad) de los mensajes: 
Tabla 1. Indicadores métricos y variables de contingencia del análisis multimodal

\begin{tabular}{|c|c|c|c|c|c|}
\hline \multirow{2}{*}{$\begin{array}{c}\text { Twitter y } \\
\text { páginas web } \\
\text { institucionales }\end{array}$} & $\begin{array}{c}\text { Tweets de los } \\
\text { líderes y } \\
\text { portavoces }\end{array}$ & $\begin{array}{c}\text { Métrica de } \\
\text { usuarios }\end{array}$ & \multirow{2}{*}{ Temática } & \multirow{2}{*}{ Finalidad } & \multirow{2}{*}{$\begin{array}{l}\text { Lenguaje } \\
\text { (hashtags y } \\
\text { menciones / } \\
\text { elementos } \\
\text { textuales) }\end{array}$} \\
\hline & $\begin{array}{l}\text { Publicaciones de } \\
\text { gestión de la } \\
\text { onda vírica }\end{array}$ & $\begin{array}{l}\text { Indicadores } \\
\text { valorativos y } \\
\text { formales }\end{array}$ & & & \\
\hline
\end{tabular}

Fuente: Elaboración propia

La muestra en Twitter se compone de 975 mensajes (tweets), distribuidos de la siguiente manera: Seibert 224, Sánchez 312, Costa 250 y Johnson 189. En el caso de las publicaciones, su tamaño es menor (n=427), repartiéndose de forma más homogénea: Bundesregierung 105, La Moncloa 107, República Portuguesa 91, y GOV.UK 124. Por tanto, el volumen por países es relativamente similar, lo que permite trazar comparaciones sobre la comunicación institucional ejercida en torno a la segunda ola de la Covid-19.

Este estudio incluye los tweets propios y las respuestas de los candidatos, pero no los retweets, puesto que su información no conecta necesariamente con la agenda de los actores políticos (Larsson e Ihlen, 2015). La recogida de la muestra en esta red social se efectúa mediante la versión de pago de Twitonomy, analizándose posteriormente con el software estadístico IBM SPSS Statistics, versión 25. Se ha desarrollado además una ficha específica con categorías excluyentes para las unidades de análisis (tabla 2), sean tweets o contenido web, fundamentada en otras investigaciones sobre la red social Twitter (Carral y Tuñón-Navarro, 2020).

Tabla 2. Categorías definidas para el análisis de contenido (temas y objetivos)

\begin{tabular}{|l|l|}
\hline \multicolumn{1}{|c|}{ Temas } & \multicolumn{1}{c|}{ Objetivos del mensaje } \\
\hline 1. Teorías de la conspiración & 1. Difundir sus encuentros políticos \\
\hline 2. Relaciones exteriores & $\begin{array}{l}\text { 2. Promocionar su presencia en medios de } \\
\text { comunicación }\end{array}$ \\
\hline 3. Inmigración / seguridad & 3. Promover acuerdos \\
\cline { 1 - 1 } $\begin{array}{l}\text { 4. Economía / industria y sector } \\
\text { servicios }\end{array}$ & 4. Anunciar medidas legislativas \\
\cline { 1 - 1 } 5. Educación & 5. Evaluar la situación \\
\hline 6. Servicios sociales & 6. Confrontar con rivales políticos \\
\cline { 1 - 1 } 7. Medioambiente & 7. Aludir a cuestiones de estrategia de gobierno \\
\hline 8. Acciones sanitarias & 8. Otros \\
\hline 9. Rivales políticos & \multicolumn{2}{|l}{} \\
\cline { 1 - 2 } 10. Eventos & \multicolumn{1}{|c|}{ 11. Otros }
\end{tabular}

Fuente: Elaboración propia

Con respecto al estudio cualitativo del lenguaje, en Twitter se analizan los hashtags y perfiles mencionados de la muestra, mientras que en las publicaciones de las webs se evalúan los contenidos 
en una selección similar a través de tres variables definidas como clave: orden y forma, sentido y estilo (van Dijk, 2015). Como marco general se aplica un análisis crítico del discurso (Flowerdew y Richardson, 2017), que también ha sido utilizado en estudios transnacionales (Alonso-Muñoz y Casero-Ripollés, 2020). Se busca debatir así sobre la construcción de dichos mensajes por parte de los actores públicos, apoyándonos después en los hallazgos cuantitativos relativos a los temas y propósitos comunicativos.

\section{Resultados}

\subsection{Descripción de la muestra y análisis cualitativo}

Los resultados en Twitter indican que Sánchez, Costa y Johnson presentan una proporción bastante semejante entre mensajes con tono positivo y neutro, marcando sus prácticas comunicativas en el período seleccionado. Este análisis del sesgo permite entender el encuadre en el que se ha gestionado una situación de crisis. Johnson muestra una ligera predisposición por el enfoque positivo $(47,1 \%$ a 43,9\%), mientras que el portugués Costa orienta esa balanza a posiciones neutras $(46,4 \%$ a $41,6 \%)$. Los mensajes positivos se corresponden con referencias optimistas, que destacan que las medidas sanitarias están dando buenos resultados o subrayan la esperanza que suponen la vacunas. Por ejemplo, en un tweet del 30 de diciembre de 2020 Jonhson afirmaba que la aprobación de AstraZeneca era una "noticia fantástica" y "un triunfo de la ciencia", siendo por tanto categorizado bajo el tono positivo.

Por su parte, el tono neutral concierne aquellos mensajes que no aplican visiones optimistas, pero tampoco incluyen críticas o valoraciones negativas, identificadas como propias del enfoque negativo. En este sentido, el comportamiento más diferencial se experimenta en el portavoz alemán Seibert, que claramente prefiere los tweets de sesgo neutral (62,9\%). Ejemplos de ello son los mensajes que enuncian los asuntos tratados en las reuniones del Consejo Europeo, tal como el difundido el 10 de diciembre de ese año: "Acuerdo del Consejo Europeo: presupuesto, fondo de desarrollo y mecanismo de condicionalidad acordados por unanimidad \#EUCO” (traducción al español). Esto revela que la estrategia germana en esta red social dejó más de lado el optimismo ante la pandemia, observable en otros actores políticos del continente, y se centró en la agenda política.

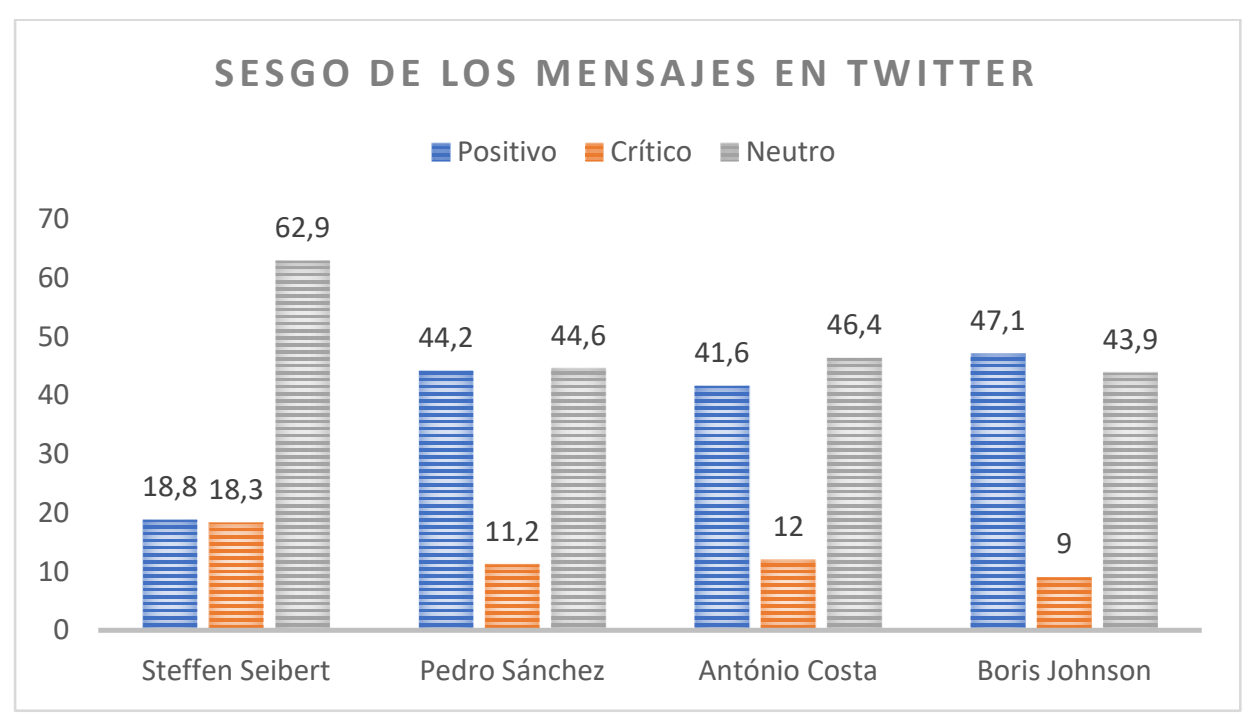

Gráfico 1: Distribución del sesgo de los tweets en relación al perfil (\%)

Fuente: Elaboración propia 
Por países, la cuenta de Steffen Seibert tiene un tono escasamente personal. Los hashtags más referenciados son muy generalistas, haciendo alusión a la pandemia (\#Corona) y la canciller (\#Merkel). Aparecen también algunos marcadores temáticos referidos a las vacunas (\#Imfgung), la digitalización (\#Digitalisierung) y, sobre todo, la implementación de medidas para aliviar los efectos de la pandemia (\#barrierefrei). No suelen visualizarse menciones directas, si bien la mayoría de las detectadas refiere a órganos federales alemanes (@BMBF_Bund, BMJV_Bund, etc.). En cambio, el contenido web de Bundesregierung presenta varias publicaciones que recogen el sentir ciudadano ante la pandemia, planteándose en un estilo informal a partir de declaraciones textuales. El propósito apreciado es el de concienciar a la población, lo que se acompaña de numerosas evaluaciones de la situación por parte de Merkel.

Con respecto a España, el perfil de Pedro Sánchez en Twitter se muestra bastante institucional, haciendo un repaso a su actividad diaria y a efemérides (\#DíaDelMigrante, \#DíaDeLosDerechosHumanos). Por ello, no hay una continuidad en los hashtags empleados, si bien se observa un uso superior de los ligados a la pandemia (\#COVID19) y las instituciones europeas (\#EUCO). Esto entronca con las menciones, más presentes en este caso y dirigidas a figuras comunitarias (@MichelBarnier, @vonderleyen) u otros presidentes europeos (@EmmnuelMacron). Este cariz gubernamental se repite en el portal La Moncloa, donde principalmente se da cuenta de la acción de los ministerios para hacer frente a la pandemia. Se sigue predominantemente la estructura de sujeto, verbo y predicado, con un sentido informativo y un estilo formal (imagen 1). Ese tono institucional es una constante tanto en las publicaciones web analizadas como en @ sanchezcastejon que, no obstante, sí incorpora en ocasiones elementos más valorativos.

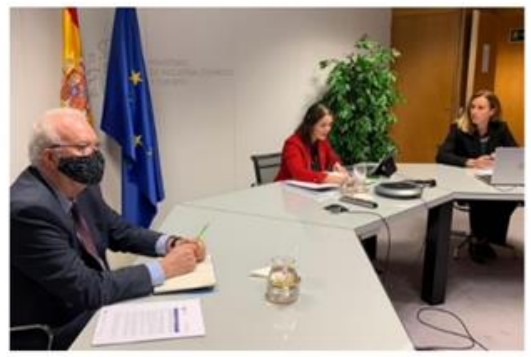

$\underline{\text { Inicio }}>$ Prensa $>$ Actualidad $>\underline{\text { Industria. }}$. Comercio y Turismo

El Gobierno sitúa a las Pymes en el centro de la recuperación económica post-Covid

Lunes 14 de diciembre de 2020

La ministra de Industria, Comercio y Turismo, Reyes Maroto, ha avanzado que el impulso a las pymes contará con una dotación de recursos públicos de 2.894 millones de euros para los próximos tres años.

\section{Imagen 1: Publicación web del Gobierno de España acerca de medidas económicas para la recuperación.}

Fuente: La Moncloa, https://bit.ly/2Pu3Q8d

En Portugal, António Costa utiliza su cuenta en Twitter de una manera ligeramente menos institucional, con más valoraciones en apariencia personales sobre la situación, lo que no es óbice para una preponderancia de hashtags relativos al propio país (\#Portugal), la pandemia (\#COVID19) y el proyecto europeo (\#UE, \#EUCO, \#UE2021PT, \#Brexit, \#Bruxelas), en tanto Portugal asumía en los meses siguientes de 2021 la presidencia del Consejo de la UE (imagen 2). Se explican de esta forma las citas directas a figuras europeas (@vonderleyen, @ Lagarde), pero también se advierten al gobierno portugués (@govpt) y los sindicatos (@CGTP_In), siendo Costa el líder seleccionado que más emplea la posibilidad de las menciones en Twitter. En cuanto a la web gubernamental República Portuguesa, cumple una función clásica de anunciar medidas del ejecutivo y brindar la agenda de sus componentes mediante un estilo formal. En consecuencia, su misión es institucional, aunque destaca el uso de citas personales de ministros y vídeos que proporcionan una perspectiva individualizada. 


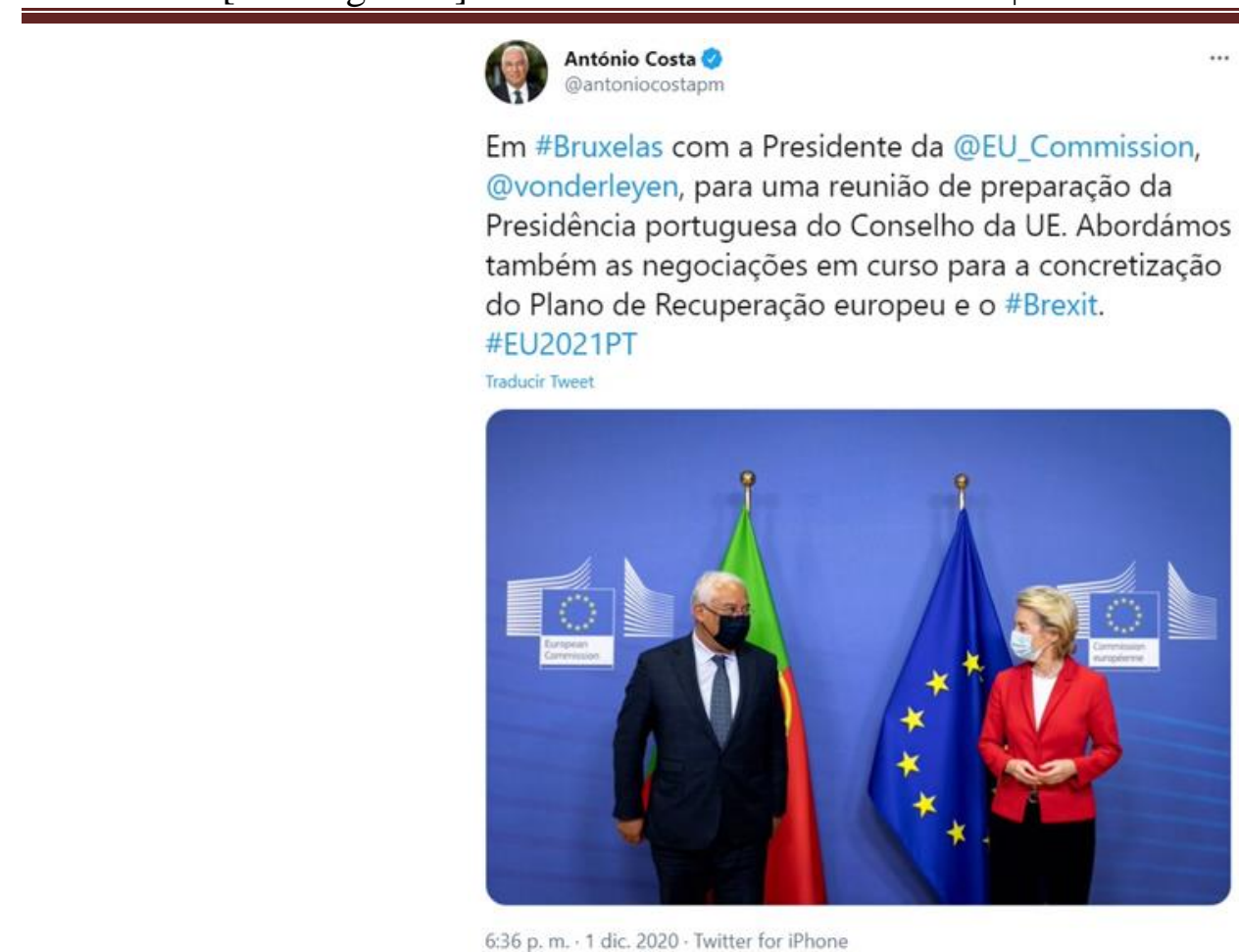

Imagen 2: Tweet de António Costa relativo a una reunión europea para el Plan de Recuperación.

Fuente: Twitter (@antoniocostapm), https://bit.ly/3rlkqos

Por su parte, el uso de Twitter por Boris Johnson puede ser interpretado como emotivo y personal, lleno de adjetivos calificativos. En este sentido, resultan habituales términos como "inolvidable", "sin precedentes", "brillante" o "fantástico". No emplea los hashtags y las menciones de manera habitual, sino que se circunscribe a momentos puntuales como cumbres internacionales (\#G20) o sesiones abiertas de preguntas y respuestas al primer ministro (\#PeoplesPMQs), así como a figuras que en algún momento captan la atención, como líderes internacionales (@ narendramodi) o empresas farmacéuticas (@Pfizer, @AstraZeneca). Los mensajes sobre las cuestiones más ásperas del virus no vienen acompañados de estas modalidades expresivas, presentando únicamente texto. De hecho, esto se repite en el portal GOV.UK. Las novedades sobre la Covid-19 se exponen en piezas esquemáticas, que distribuyen los datos en puntos con un estilo sobrio y sencillo, evidenciando una finalidad informativa.

Esta aproximación cualitativa busca ofrecer una primera panorámica de cómo se articularon durante el período fijado dos posibles mecanismos de rendición democrática (cuentas en Twitter y páginas web oficiales), revelando líneas de investigación relevantes. A continuación, se contrastan cuantitativamente esos hallazgos, a la vez que se detectan otros.

\subsection{Temáticas y objetivos de la comunicación gubernamental}

El análisis de la agenda y las finalidades de los mensajes arrojan datos relevantes, que reflejan divergencias de interés. En primer lugar, la distribución temática de los tweets muestra que la mayor parte de los representantes se centran en las acciones sanitarias a raíz de la pandemia (tabla 3): 42,4\% de los mensajes en Seibert, 28,8\% en Costa y 41,8\% en Johnson. El único líder que no lo sitúa entre sus dos asuntos preferentes es Sánchez, que publica más sobre las relaciones exteriores $(20,5 \%)$ y economía (20,8\%). En cualquier caso, sintoniza a grandes rasgos con la estrategia de otros líderes, puesto que también Seibert $(19,6 \%)$ y Johnson $(16,4 \%)$ conceden gran espacio a las relaciones exteriores, mientras que Costa lo hace a la economía (19,2\%). Además, todos coinciden en dedicar más 
del $10 \%$ de sus tweets a eventos. Se denota una estrategia temática bastante similar, con la salvedad de una mayor preocupación por las cuestiones económicas en las personalidades de la Península Ibérica, quizás motivada por un impacto financiero superior de la crisis de la Covid-19 en estos países.

Tabla 3. Distribución de los tweets de representantes institucionales en función de su temática y objetivos (\%). *Los porcentajes en negrita indican los datos destacados para este estudio

\begin{tabular}{|c|c|c|c|c|c|}
\hline & & $\begin{array}{l}\text { Steffen } \\
\text { Seibert }\end{array}$ & $\begin{array}{c}\text { Pedro } \\
\text { Sánchez }\end{array}$ & $\begin{array}{l}\text { António } \\
\text { Costa }\end{array}$ & $\begin{array}{c}\text { Boris } \\
\text { Johnson }\end{array}$ \\
\hline \multirow{9}{*}{ Temática } & Relaciones exteriores & 19,6 & 20,5 & 12,4 & 16,4 \\
\hline & Inmigración / seguridad & 6,7 & 1,9 & 2,8 & 5,3 \\
\hline & Economía & 8,0 & 20,8 & 19,2 & 6,3 \\
\hline & Servicios sociales & 2,7 & 8,3 & 12,4 & 5,8 \\
\hline & Medioambiente & 2,2 & 3,5 & 4,4 & 6,3 \\
\hline & Acciones sanitarias & 42,4 & 13,1 & 28,8 & 41,8 \\
\hline & Rivales políticos & 0,0 & 5,8 & 1,2 & 1,1 \\
\hline & Eventos & 15,6 & 13,8 & 13,2 & 11,1 \\
\hline & Otros & 2,7 & 12,2 & 5,6 & 5,8 \\
\hline \multirow{9}{*}{ Objetivos } & $\begin{array}{l}\text { Difundir encuentros } \\
\text { políticos }\end{array}$ & 12,9 & 11,5 & 16,0 & 13,8 \\
\hline & Presencia en medios & 8,5 & 3,2 & 3,2 & 6,9 \\
\hline & Promover acuerdos & 2,2 & 7,4 & 5,6 & 2,6 \\
\hline & $\begin{array}{ll}\text { Anunciar } & \text { medidas } \\
\text { legislativas } & \end{array}$ & 18,8 & 14,4 & 20,4 & 29,6 \\
\hline & Evaluar la situación & 29,9 & 17,3 & 14 & 22,2 \\
\hline & $\begin{array}{ll}\text { Confrontar } & \text { rivales } \\
\text { políticos } & \end{array}$ & 0,0 & 5,1 & 0,4 & 1,1 \\
\hline & $\begin{array}{l}\text { Aludir a estrategia de } \\
\text { gobierno }\end{array}$ & 2,7 & 12,8 & 5,6 & 7,4 \\
\hline & Referenciar a la UE & 21,0 & 14,4 & 26,8 & 2,6 \\
\hline & Otros & 4 & 13,8 & 8,0 & 13,8 \\
\hline
\end{tabular}

Fuente: Elaboración propia

Las semejanzas también se aprecian en los objetivos, pero en este ámbito la disparidad es ligeramente superior. Seibert $(29,9 \%)$ y Sánchez $(17,3 \%)$ concentran sus mensajes en la evaluación de la situación. Por su parte, Costa $(20,4 \%)$ y Johnson $(29,6 \%)$ tuitean más para anunciar medidas legislativas. No obstante, estos dos propósitos (evaluar y presentar acciones) se antojan fundamentales en los cuatro líderes. Asimismo, la difusión de encuentros políticos ocupa posiciones destacadas.

El ítem con un volumen de alusión más heterogéneo es el de referencias a la UE. Para Costa constituye su principal objetivo (26,8\%), seguido de Seibert (21\%). Ambos muestran una actividad en Twitter que cita con frecuencia a la Unión Europea en la gestión de la pandemia. En contraste, Johnson prácticamente no menciona a la UE $(2,6 \%)$, lo que es destacable en el contexto del Brexit. Las prácticas del primer ministro británico encajan más con las del conjunto de la muestra, que revelan una predilección por los elementos sanitarios, con las mencionadas finalidades de valoración y propuestas legislativas (imagen 3). 
Apresentámos hoje o Plano Nacional de Vacinação contra a \#COVID19. \#Portugal vai adquirir 22 milhões de vacinas que vão chegando progressivamente ao longo de 2021. A operação de vacinação vai desenvolver-se também ao longo do ano. Traducir Tweet

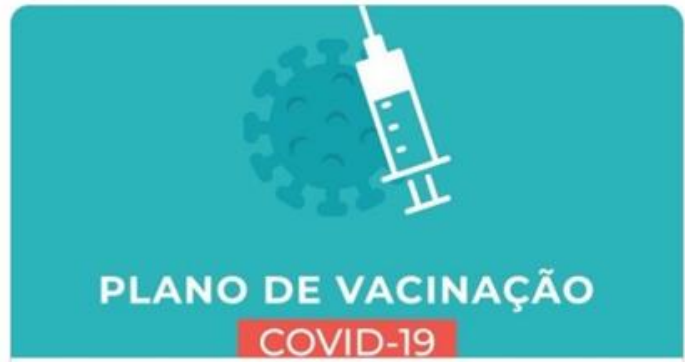

Plano Vacinaçăo Covid 19 - Covid 19 estamos ON

O Plano de Vacinaçăo Covid-19 foi apresentado no dia 3 de dezembro pel equipa coordenadora que o desenhou, pela Ministra da Saúde e pelo Primeirc... O covid19estamoson.gov.pt

8:30 p.m. 3 dic. 2020 . Twitter for iphone

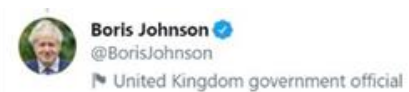

En respuesta a @Borisjohnson

You may leave your home for work, for exercise, with your household or on your own with one person from another household, to shop for food and essentials, for medical care and to provide care for others. (3/10)

\section{raducir Tweet}

9:57 p. m. 31 oct. 2020 - Twitter Web App

108 Retweets 33 Tweets citados 716 Me gusta

Imagen 3: Tweets de António Costa y Boris Johnson sobre medidas legislativas (objetivo) de acciones sanitarias (temática): plan de vacunación y normas de confinamiento.

Fuente: Twitter (@antoniocostapm y @BorisJohnson), https://bit.ly/304zBXk y https://bit.ly/382nDls

Las webs institucionales prosiguen con la tendencia observada en Twitter. De acuerdo con los datos recabados por nuestra investigación (tabla 4), se mantiene una predisposición hacia las acciones sanitarias, con porcentajes superiores en los portales gubernamentales: $40 \%$ en Bundesregierung, $32,1 \%$ en La Moncloa, $56 \%$ en República Portuguesa y 46,8\% en GOV.UK. Esto conlleva una concentración temática en las webs, es decir, en Twitter se abordaba un mayor número de asuntos con volúmenes elevados. La economía vuelve a ser el segundo tema preferido, con porcentajes también mayores. Sobresale aquí la frecuencia del medioambiente en La Moncloa (19,2\%), un hecho no localizado en el perfil de Sánchez. 
RLCS, Revista Latina de Comunicación Social, 79, 49-72

[Investigación] DOI: 10.4185/RLCS-2021-1517| ISSN 1138-5820| Año 2021

Tabla 4. Distribución de las publicaciones web institucionales en función de su temática y objetivos (\%). * Los porcentajes en negrita indican los datos destacados para este estudio

\begin{tabular}{|c|c|c|c|c|c|}
\hline & & $\begin{array}{l}\text { Bundes- } \\
\text { regierung }\end{array}$ & La Moncloa & $\begin{array}{c}\text { República } \\
\text { Portuguesa }\end{array}$ & GOV.UK \\
\hline \multirow{9}{*}{ Temática } & Relaciones exteriores & 13,3 & 18,6 & 6,6 & 13,7 \\
\hline & Inmigración / seguridad & 0,0 & 0,0 & 0,0 & 0,0 \\
\hline & Economía & 20,0 & 18,6 & 31,9 & 26,6 \\
\hline & Servicios sociales & 13,4 & 11,5 & 0,0 & 0,0 \\
\hline & Medioambiente & 0,0 & 19,2 & 0,0 & 12,9 \\
\hline & Acciones sanitarias & 40,0 & 32,1 & 56,0 & 46,8 \\
\hline & Rivales políticos & 6,7 & 0,0 & 0,0 & 0,0 \\
\hline & Eventos & 6,7 & 0,0 & 0,0 & 0,0 \\
\hline & Otros & 0,0 & 0,0 & 5,5 & 0,0 \\
\hline \multirow{9}{*}{ Objetivos } & $\begin{array}{l}\text { Difundir encuentros } \\
\text { políticos }\end{array}$ & 6,7 & 6,4 & 12,1 & 6,5 \\
\hline & Presencia en medios & 0,0 & 0,0 & 0,0 & 0,0 \\
\hline & Promover acuerdos & 6,7 & 0,0 & 0,0 & 0,0 \\
\hline & $\begin{array}{ll}\text { Anunciar } & \text { medidas } \\
\text { legislativas } & \\
\end{array}$ & 18,2 & 19,5 & 27,3 & 40,3 \\
\hline & Evaluar la situación & $\mathbf{4 1 , 8}$ & 26,7 & 30,8 & 25,8 \\
\hline & $\begin{array}{ll}\text { Confrontar rivales } \\
\text { políticos }\end{array}$ & 0,0 & 0,0 & 0,0 & 0,0 \\
\hline & $\begin{array}{l}\text { Aludir a estrategia de } \\
\text { gobierno }\end{array}$ & 0,0 & 30,8 & 6,6 & 13,7 \\
\hline & Referenciar a la UE & 26,7 & 16,6 & 23,3 & 13,7 \\
\hline & Otros & 0,0 & 0,0 & 0,0 & 0,0 \\
\hline
\end{tabular}

Fuente: Elaboración propia

En lo referente a los objetivos de las publicaciones web, se repite un predominio de los anuncios de iniciativas $\mathrm{y}$, especialmente, de las evaluaciones de la coyuntura. Al igual que sucedía en las temáticas, los porcentajes de estas finalidades son mayores en los portales institucionales frente a Twitter, evidenciando una concentración en ciertos ítems para dichas webs. Un objetivo diferencial es el alto volumen de referencias a la UE en los gobiernos alemán $(26,7 \%)$ y portugués $(23,3 \%)$, algo que se corresponde con lo visto en las cuentas de Seibert y Costa.

Otro rasgo característico pasa por las alusiones a estrategia de gobierno en la web La Moncloa, que se erigen en su meta más habitual $(30,8 \%)$. Este patrón, que consiste en mencionar prioridades del gobierno o analizar su cumplimiento del programa electoral, solo era observable a menor nivel en el perfil de Sánchez en Twitter. Esto conecta con un encuadre orientado hacia asuntos temáticos $(62,2 \%)$, y marcadamente opinativo $(63,5 \%)$ en el portal institucional español, según nuestro análisis de indicadores formales (titulares) en las piezas sobre Covid-19 (tabla 5). La inclinación por esos componentes factuales de la política se aprecia en Bundesregierung (60\%), si bien su tipología es eminentemente informativa $(53,3 \%)$, presentando los niveles más bajos de valoración, lo que concuerda con el carácter neutral localizado en el portavoz alemán. 
RLCS, Revista Latina de Comunicación Social, 79, 49-72

[Investigación] DOI: 10.4185/RLCS-2021-1517| ISSN 1138-5820| Año 2021

Tabla 5. Enfoque y tipología de titulares en las webs institucionales (\%). * Los porcentajes en negrita indican los datos destacados para este estudio

\begin{tabular}{|c|l|c|c|c|c|}
\hline \multirow{4}{*}{ Titular } & $\begin{array}{c}\text { Bundes- } \\
\text { regierung }\end{array}$ & La Moncloa & $\begin{array}{c}\text { República } \\
\text { Portuguesa }\end{array}$ & GOV.UK \\
\hline & $\begin{array}{l}\text { Enfocado en } \\
\text { personalidad política }\end{array}$ & 26,7 & 31,4 & $\mathbf{5 6 , 0}$ & $\mathbf{6 7 , 7}$ \\
\cline { 2 - 6 } & $\begin{array}{l}\text { Enfocado en asuntos } \\
\text { temáticos }\end{array}$ & $\mathbf{6 0 , 0}$ & $\mathbf{6 2 , 2}$ & 37,4 & 32,3 \\
\cline { 2 - 6 } & $\begin{array}{l}\text { Sin objeto de atención } \\
\text { claro }\end{array}$ & 13,3 & 6,4 & 6,6 & 0,0 \\
\hline \multirow{3}{*}{$\begin{array}{c}\text { Tipo de } \\
\text { titular }\end{array}$} & Informativo & $\mathbf{5 3 , 3}$ & 23,7 & 37,4 & $\mathbf{5 2 , 4}$ \\
\cline { 2 - 6 } & Interpretativo & 13,3 & 12,8 & 5,5 & 0,0 \\
\cline { 2 - 7 } & Opinativo / valorativo & 33,3 & $\mathbf{6 3 , 5}$ & $\mathbf{5 7 , 1}$ & 47,6 \\
\hline
\end{tabular}

Fuente: Elaboración propia

Por otro lado, los portales de República Portuguesa (56\%) y GOV.UK $(67,7 \%)$ suelen enfocar su información en personalidades políticas, ya sea el primer ministro o miembros de su gabinete, con cifras temáticas que superan además el $30 \%$ en los dos casos. Por el contrario, estos países difieren sensiblemente en la finalidad del titular, puesto que en Reino Unido prevalece un enfoque informativo (52,4\%), algo en consonancia con el estilo austero comentado en el análisis cualitativo. En Portugal la tipología mayoritaria es valorativa $(57,1 \%)$, lo que no imposibilita contar con un porcentaje relevante de titulares informativos $(37,4 \%)$. Así pues, la construcción de los contenidos en las webs institucionales presenta divergencias en los cuatro países seleccionados, desarrollándose con distintos encuadres y propósitos.

\subsection{Fuentes informativas e intereses de los ciudadanos}

Para completar el estudio, cumple determinar cuál es el grado de atención de la ciudadanía por los mensajes institucionales, y si se relaciona con las estrategias empleadas. Mediante el número de retweets, los resultados muestran que el interés de la audiencia en esta red social no se correlaciona con los objetivos preferentes de los líderes (tabla 6). Las finalidades que cuentan con más retweets son la confrontación con los rivales políticos $(84,2 \%$ de sus mensajes por encima de 300 interacciones) y la alusión a la estrategia de gobierno $(66,2 \%)$. Se difiere del anuncio de medidas legislativas $(38,1 \%)$ y la evaluación de la situación $(47 \%)$, que suponían las dos misiones prioritarias para los líderes en Twitter. Cabe resaltar que estas variables presentan niveles notables de aparición (33\% y 25,3\%, respectivamente) en la franja de menor interacción entre 1 y 49 retweets.

Nuestro estudio de la atención ciudadana en Twitter se focaliza en los objetivos de los mensajes, que permiten valorar en profundidad las motivaciones que hay detrás de los tweets que generan una mayor atención. Consideramos que en este caso dicha aproximación, basada en los tipos de mensajes preferidos, resulta más pertinente que el análisis temático, dado que este puede someterse a oscilaciones en función del número de seguidores y eventos de naturaleza inesperada. 
RLCS, Revista Latina de Comunicación Social, 79, 49-72

[Investigación] DOI: 10.4185/RLCS-2021-1517| ISSN 1138-5820| Año 2021

Tabla 6. Frecuencia de retweets según el objetivo del mensaje (\%). * Los porcentajes en negrita indican los datos destacados para este estudio

\begin{tabular}{|l|c|c|c|c|}
\hline & $\begin{array}{c}\mathbf{1 - 4 9} \\
\text { retweets }\end{array}$ & $\begin{array}{c}\mathbf{5 0 - 9 9} \\
\text { retweets }\end{array}$ & $\begin{array}{c}\mathbf{1 0 0 - 2 9 9} \\
\text { retweets }\end{array}$ & $\begin{array}{c}\mathbf{3 0 0} \text { o más } \\
\text { retweets }\end{array}$ \\
\hline Difundir encuentros políticos & 35,9 & 8,4 & 27,5 & 28,2 \\
\hline Presencia en medios & 36,0 & 16,0 & 10,0 & 38,0 \\
\hline Promover acuerdos & 40,4 & 12,8 & 6,4 & 40,4 \\
\hline Anunciar medidas legislativas & $\mathbf{3 3 , 0}$ & 7,7 & 21,1 & 38,1 \\
\hline Evaluar la situación & $\mathbf{2 5 , 3}$ & 3,5 & 24,2 & 47,0 \\
\hline Confrontar rivales políticos & 5,3 & 0,0 & 10,5 & $\mathbf{8 4 , 2}$ \\
\hline Aludir a estrategia de gobierno & 12,2 & 5,4 & 16,2 & $\mathbf{6 6 , 2}$ \\
\hline Referenciar a la UE & $\mathbf{5 6 , 7}$ & 11,6 & 12,2 & 19,5 \\
\hline Otros & 18,4 & 3,1 & 26,5 & 52,0 \\
\hline
\end{tabular}

Fuente: Elaboración propia

Asimismo, resulta subrayable el alto nivel de interacción de la categoría "otros" (52\% por encima de los 300 retweets), vinculado a efemérides como la celebración de días mundiales o los aniversarios, ya que esta ha sido la categoría que ha contenido todos esos tópicos. Se trata de asuntos en positivo que conllevan una cascada de reacciones, alejándose de propósitos más políticos. Por su parte, se observa un escaso interés en las referencias a la UE, hasta el punto que suponen el objetivo con más retweets en el escalafón inferior (56,75\%). Estos mensajes sobre la Unión aluden a reuniones como las del Consejo Europeo (imagen 4), en las que se elaboran medidas coordinadas para la gestión de la pandemia.

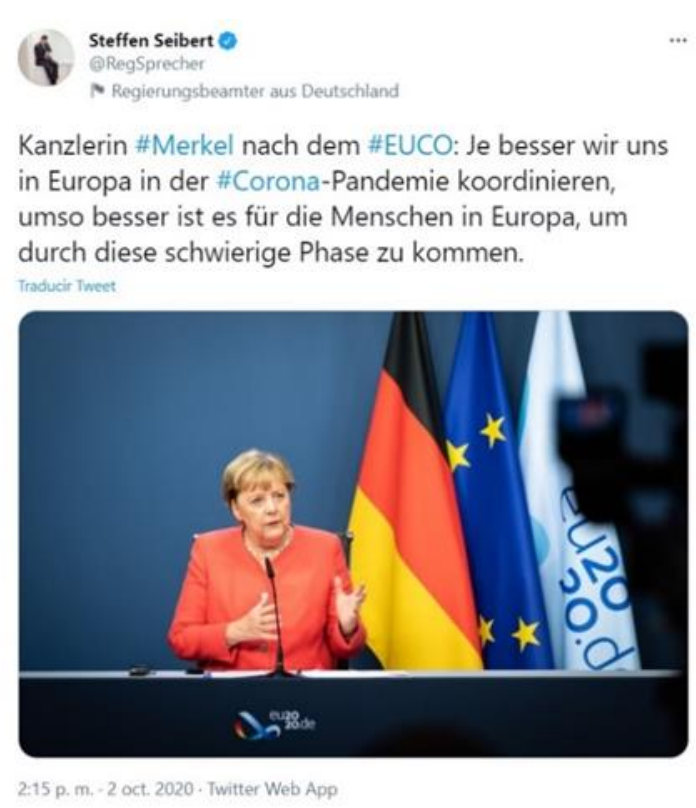

Imagen 4: Tweet de Steffen Seibert aportando declaraciones de Merkel tras un Consejo Europeo. Fuente: Twitter (@RegSprecher), https://bit.ly/2MDyavO

Los resultados anteriores denotan que el interés ciudadano no se corresponde con el político en el marco de nuestra investigación. Esto puede conectar con un desinterés estructural por estas cuestiones, que limitaría el impacto de la comunicación institucional (Jacobs y Wonneberger, 2019). En esta dirección podría analizarse el volumen de retweets por líder, pero las importantes variaciones en su número de seguidores explicarían en parte sus cifras. Por ello, se ha optado por conocer la presencia de 
la ciudadanía y de otros actores en la configuración de las estrategias comunicativas en sus portales en la Red (tabla 7). Los jefes de Gobierno funcionan como la principal fuente de información en Bundesregierung (33,3\%), República Portuguesa (42,9\%) y GOV.UK $(73,4 \%)$, es decir, tanto Merkel como Costa y Johnson se articulan en el principal origen de datos para la comunicación web de sus gobiernos.

Tabla 7. Tipología de fuentes preferente en cada web gubernamental (\%). * Los porcentajes en negrita indican los datos destacados para este estudio

\begin{tabular}{|l|c|c|c|c|}
\hline & $\begin{array}{c}\text { Bundes- } \\
\text { regierung }\end{array}$ & La Moncloa & $\begin{array}{c}\text { República } \\
\text { Portuguesa }\end{array}$ & GOV.UK \\
\hline Jefe de Gobierno & $\mathbf{3 3 , 3}$ & 6,4 & $\mathbf{4 2 , 9}$ & $\mathbf{7 3 , 4}$ \\
\hline Políticos nacionales & 20,0 & 19,2 & 38,5 & 6,5 \\
\hline Técnicos (expertos) & 13,3 & 6,4 & 0,0 & 0,0 \\
\hline Organismos nacionales & 20,0 & $\mathbf{6 7 , 9}$ & 18,7 & 20,2 \\
\hline Ciudadanos & $\mathbf{1 3 , 3}$ & 0,0 & 0,0 & 0,0 \\
\hline
\end{tabular}

Fuente: Elaboración propia

En comparación con la tendencia previa, en La Moncloa prevalecen los organismos nacionales $(67,9 \%)$. Le siguen en proporción los políticos nacionales como los ministros $(19,2 \%)$, que también ocupan posiciones destacadas en Bundesregierung (20\%) y República Portuguesa (38,5\%), mientras que el uso del jefe de Gobierno en España es reducido (6,4\%). Además, los organismos nacionales demuestran ser fuente frecuente en toda la muestra.

Las variables que ofrecen mayores singularidades se atribuyen a perfiles técnicos (expertos) y ciudadanos. Los expertos aparecen en Bundesregierung (13,3\%), y a menor nivel en La Moncloa $(6,4 \%)$. En cuanto a los ciudadanos como origen informativo, únicamente son referenciados en el portal alemán (13,3\%). La imagen 5 ejemplifica su utilización con fines de concienciación social, al citar la experiencia personal de un joven que superó la Covid-19.

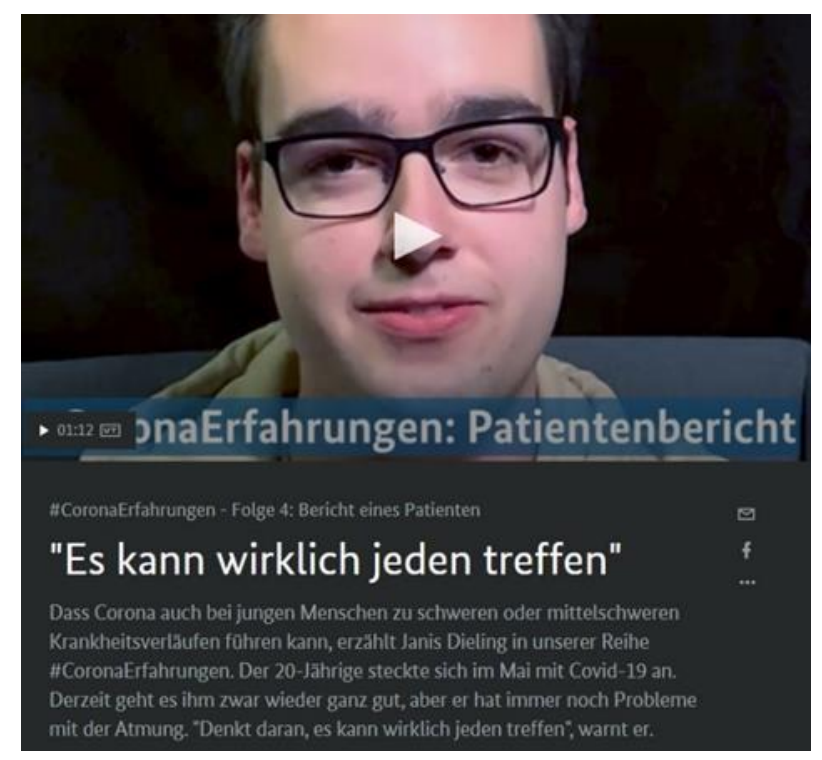

Imagen 5: Publicación web del gobierno federal alemán en torno a una experiencia personal del virus.

Fuente: Bundesregierung, https://bit.ly/3bdMRPX 
El relato del individuo se expone en primera persona, con datos personales de la persona interviniente, de la cual se aportan declaraciones en vídeo y transcripción de los aspectos más importantes enunciados. Como se ha comentado, se aprecia una voluntad de sensibilizar a la población sobre la pandemia a través de sujetos comunes identificables con el público. Esto es relevante, dado que la literatura enfatiza el papel de la audiencia en la difusión de lo falso (Pérez-Curiel y Velasco Molpeceres, 2020), algo que ha quedado de manifiesto en la "infodemia" espoleada por la Covid-19 (Nielsen et al., 2020).

En consecuencia, no se produce una aparición de los ciudadanos como objetos de atención en las webs institucionales, tras detectar en Twitter que sus intereses discrepan en parte de los predilectos por la clase política en el tratamiento de la pandemia. Estos hallazgos, junto con la preponderancia de jefes de Gobierno y organismos nacionales como fuente, invitan a reflexionar acerca de la vinculación de la comunicación implementada con la audiencia a la que se dirige.

\section{Discusión y conclusiones}

En un contexto de crisis sanitaria y económica, los resultados obtenidos posibilitan responder a las cuestiones formuladas para comparar algunas de las acciones comunicativas de diferentes gobiernos europeos en torno a la segunda ola de Covid-19. En relación a la primera pregunta de investigación acerca de si los mensajes digitales se organizan en torno a los mismos temas, objetivos y discursos, se observan diferencias de interés por países. Para la red social Twitter, el tono de Seibert (Alemania) y Sánchez (España) se muestra institucional, frente al carácter más personal de Costa (Portugal) y Johnson (Reino Unido). No obstante, la distribución temática de todas estas figuras se concentra en las acciones sanitarias, la economía y las relaciones exteriores, con ligeras diferencias en Sánchez. Los propósitos de esos mensajes reflejan una lógica compartida, que gira acerca de los anuncios legislativos y la evaluación de la situación. En esta variable emergen además las referencias a la UE, notorias en los casos portugués y alemán. A todo ello se suma el análisis del tono como encuadre comunicativo, muy equilibrado entre sesgos positivos y negativos en Sánchez, Costa y Johnson. El germano Seibert se desmarca de la citada tendencia, con una preponderancia del enfoque neutral.

En cuanto a los espacios web, sus contenidos exponen diferencias para cada uno de los cuatros países de la muestra. El enfoque en personalidades políticas de República Portuguesa y GOV.UK se canaliza en el caso británico de manera informativa, en tanto que el portal portugués apuesta por un mayor peso valorativo. Bundesregierung y La Moncloa se inclinan por los asuntos factuales, si bien el gobierno alemán muestra preferencia por el componente informativo y el español lo hace por el valorativo.

Como segunda aportación, se aprecia que sí existen adaptaciones de la estrategia institucional en función de la herramienta (Twitter o web). Aunque los portales oficiales continúan con la dinámica de la red social, la concentración temática es superior en ellos. Las acciones sanitarias como issues, y las medidas legislativas y las valoraciones de la situación en el plano de los objetivos, alcanzan porcentajes mayores en las noticias web, evidenciando a su vez la pluralidad de la acción comunicativa en Twitter. Los asuntos y propósitos se repiten, pero la concentración de la web contrasta con la fragmentación en dicha red social. Además, se percibe un uso abundante de la estrategia de gobierno en La Moncloa, no detectada en el perfil de Sánchez.

Como tercera aportación en respuesta a la correspondencia entre el contenido difundido y los intereses de la audiencia, se experimenta una ausencia de correlación entre los objetivos de los mensajes compartidos por los líderes y aquellos que logran mayores cotas de atención de acuerdo 
con el número de retweets. Los propósitos que obtienen una interacción superior en Twitter son la confrontación con rivales políticos y la alusión a estrategias de gobierno, que no coinciden con la enunciación de medidas y la evaluación de la coyuntura priorizadas por los líderes. Esto también se observa en las referencias a la UE, habituales en Seibert y Costa, pero que constituyen el objetivo con menos retweets.

Un elemento adicional a destacar sobre el público es que los ciudadanos apenas son identificados como fuentes en los portales institucionales, con la excepción del gobierno alemán. En cambio, los jefes de Gobierno y otras figuras u organismos de carácter institucional monopolizan el flujo informativo en el período de la pandemia estimado. Esto provoca que pueda existir una potencial desconexión entre la ciudadanía y sus dirigentes, como se deduce de la distribución de los retweets por objetivos, ajena a los marcos preferentes de los líderes.

Como discusión, consideramos que el potencial para crear conversación de las plataformas digitales ha estado infrautilizado desde el punto de vista institucional, en consonancia con investigaciones anteriores (Boerman y Kruikemeier, 2016). Los temas y los objetivos se circunscriben a labores clásicas como el anuncio de propuestas, ligadas aquí al ámbito sanitario. Sin embargo, emergen hallazgos conjuntos de interés como las abundantes referencias a la UE por parte de los gobiernos alemán y portugués, de las que se deduce una pretensión de plantear una solución europea a la pandemia. Otros elementos detectados, como las alusiones a la economía en los perfiles de los líderes español y luso en Twitter, pueden conectarse con la difícil situación padecida durante la crisis del euro (2010-2014) por esos países. Ese antecedente funcionaría como factor explicativo de la preocupación económica desde el punto de vista institucional.

Nuestra investigación contribuye a las actuales discusiones sobre la gestión comunicativa gubernamental, mostrando que los portales institucionales presentan una menor pluralidad de temas y objetivos que los mensajes en Twitter. A ello se une la deficiente conexión con los intereses ciudadanos. La respuesta digital y prorrogada por parte de los gobiernos a la Covid-19 goza asimismo de diferencias por países, en función de sus culturas políticas y mediáticas. Pruebas de ello son el enfoque aséptico en Alemania, la prevalencia del personalismo político en Reino Unido o la búsqueda de soluciones comunitarias en Estados europeístas.

Las indagaciones científicas sobre la primera ola de Covid-19 subrayan la utilización de una comunicación institucional incongruente ante la pandemia (Wang et al., 2021), que abordaba una gran cantidad de datos sin la suficiente coherencia. También se detectaron planteamientos heterogéneos entre los líderes europeos en términos de medidas recomendadas y la imagen transmitida en Twitter (Drylie-Carey et al., 2020). Frente a ello, los consumidores de Internet en países como España priorizaron los contenidos que apelaban a la empatía (Losada Díaz et al., 2020). Esto explicaría la actuación personalista y propia de las celebridades culturales de líderes como Sánchez durante la primera fase de la pandemia (Manfredi-Sánchez et al., 2021), cuando los mensajes se focalizaban en la cuestión sanitaria.

En cambio, los resultados aquí presentados para la segunda onda vírica sugieren ciertos cambios, ya que la comunicación de los cuatro líderes no solo alude a aspectos sanitarios, sino también económicos. Se observan intentos de aportar propuestas o soluciones que mejoren la situación por la que atraviesa la ciudadanía, a la vez que jefes de gobierno como Sánchez transitan hacia un perfil más institucional. En cualquier caso, siguen existiendo importantes divergencias entre la comunicación aplicada por los distintos gobiernos europeos. Además, la falta de interés ciudadano por las cuestiones políticas puede implicar una dificultad añadida para lograr credibilidad y transparencia, erigidos como valores fundamentales en la gestión comunicativa de la Covid-19 
(Ataguba y Ataguba, 2020). La llegada de las vacunas al final del ciclo analizado es otro componente a considerar en la evolución de la comunicación institucional (Warren y Lofstedt, 2021).

Una limitación de nuestro estudio radica en que atiende a una muestra limitada, acotada a un momento singular. Precisamente ese carácter excepcional atribuye interés al período estudiado, pero serían necesarias investigaciones extendidas en el tiempo para comprobar la vigencia de las tendencias observadas. En segundo lugar, esta propuesta carece de herramientas para valorar el impacto de esos gobiernos en la discusión pública, algo que podría emplearse para conocer la posible relación causa-efecto con la atención generada en la audiencia. En su lugar se ha abogado por desagregar la acción comunicativa en tweets y portales web, comparándola con dos elementos de interacción y participación.

En resumen, este estudio revela las características y posibles limitaciones de varias estrategias implementadas en la segunda ola de Covid-19, a la par que identifica patrones compartidos y diferenciados en países pertenecientes a un espacio geográfico conjunto como Europa. Las plataformas digitales, sean redes sociales o portales institucionales ad hoc, pueden funcionar como mecanismos para la rendición de cuentas democrática, de ahí que resulte necesario seguir ahondando en su configuración en momentos de enorme trascendencia social.

\section{Referencias}

Aharony, N. (2012). Twitter use by three political leaders: an exploratory analysis. Online Information Review, 36(4), 587-603. https://doi.org/10.1108/14684521211254086

Alonso-Muñoz, L. y Casero-Ripollés, A. (2020). Populism against Europe in social media: The Eurosceptic discourse on Twitter in Spain, Italy, France, and United Kingdom during the campaign of the 2019 European Parliament election. Frontiers in Communication, 5(54). https://doi.org/10.3389/fcomm.2020.00054

Ataguba, O. A. y Ataguba, J. E. (2020). Social determinants of health: the role of effective communication in the COVID-19 pandemic in developing countries. Global Health Action, 13(1), 1788263. https://doi.org/10.1080/16549716.2020.1788263

Barroso Simao, L., Gouveia Rodrigues, R. y Madeira, M. J. (2016). External relationships in the organizational innovation. RAI - Revista de Administração e Inovação, 13(3), 156-165. https://doi.org/10.1016/j.rai.2016.06.002

Bennett, W. L. y Livingston, S. (2018). The disinformation order: Disruptive communication and the decline of democratic institutions. European Journal of Communication, 33(2), 122-139. https://doi.org/10.1177/0267323118760317

Bimber, B. y Gil de Zúñiga, H. (2020). The unedited public sphere. New Media \& Society, 22(4), 700-715. https://doi.org/10.1177/1461444819893980

Brantner, C. y Pfeffer, J. (2018). Content analysis of Twitter - big data, big studies. En: S. Elridge II y B. Franklin (Eds.), The Routledge Handbook of Developments in Digital Journalism Studies (79-92). Taylor \& Francis. 
Boerman, S. C. y Kruikemeier, S. (2016). Consumer responses to promoted tweets sent by brands and political parties. Computers in Human Behavior, 65, 285-294. https://doi.org/10.1016/j.chb.2016.08.033

Broersma, M. y Graham, T. (2013). Twitter as a news source: How Dutch and British newspapers used tweets in their news coverage, 2007-2011. Journalism Practice, 7(4), 446-464. https://doi.org/10.1080/17512786.2013.802481

Bruns, A., Enli, G., Skogerbö, E., Larsson, A. y Christensen, C. (Eds.) (2016). Routledge Companion to Social Media and Politics. Routledge.

Burgueño, J. M. (2014). Comunicación institucional para periodistas. Manual práctico de comunicación y relaciones públicas. UOC.

Callejo, J. (2010). Introducción a las técnicas de investigación social. Universitaria Ramón Areces.

Campos-Domínguez, E. (2017). Twitter y la comunicación política. El profesional de la información, 26(5), 785-793. https://doi.org/10.3145/epi.2017.sep.01

Carral, U. y Tuñón-Navarro, J. (2020). Estrategia de comunicación organizacional en redes sociales: análisis electoral de la extrema derecha francesa en Twitter. Profesional de la información, 29(6), e290608. https://doi.org/10.3145/epi.2020.nov.08

Casero-Ripollés, A. y García-Gordillo, M. (2021). La influencia del periodismo en el ecosistema digital. En: L. M. Pedrero-Esteban y A. Pérez-Escoda (Coords.). Cartografía de la comunicación postdigital: medios y audiencias en la sociedad de la COVID-19 (157-176). Thomson Reuters Aranzadi Civitas.

Castillo-Esparcia, A., Moreno, A. y Capriotti-Peri, P. (2020). Relaciones públicas y comunicación institucional ante la crisis del COVID-19. Revista Internacional de Relaciones Públicas, 10(19), 1-6. http://dx.doi.org/10.5783/RIRP-19-2020-01-01-06

Chadwick, A. (2017). The hybrid media system. Politics and power. Oxford University Press.

Colleoni, E., Rozza, A. y Arvidsson, A. (2014). Echo chamber or public sphere? Predicting political orientation and measuring political homophily in Twitter using big data. Journal of Communication, 64(2), 317-332. https://doi.org/10.1111/jcom.12084

Cornelissen, J. (2008). Corporate communication: A guide to theory and practice. Sage.

Crilley, R. y Gillespie, M. (2019). What to do about social media? Politics, populism and journalism. Journalism, 20(1), 173-176. https://doi.org/10.1177/1464884918807344

D'Heer, E. y Verdegem, P. (2015). What social media data mean for audience studies: a multidimensional investigation of Twitter use during a current affairs TV programme. Information, $\quad$ Communication $\& \quad$ Society, $\quad 18(2), \quad 221-234$. https://doi.org/10.1080/1369118X.2014.952318 
Díez Garrido, M., Campos Domínguez, E. y Calvo, D. (2019). La transparencia de los partidos políticos como estrategia electoral. Una evaluación de sus promesas y sus páginas web. Trípodos, 44, 83-104.

Drylie-Carey, L., Sánchez-Castillo, S. y Galán-Cubillo, E. (2020). European leaders unmasked: Covid-19 communication strategy through Twitter. Profesional de la información, 29(5), e290504. https://doi.org/10.3145/epi.2020.sep.04

Engesser, S., Ernst, N., Esser, F. y Büchel, F. (2017). Populism and social media: how politicians spread a fragmented ideology. Information, Communication \& Society, 20(8), 1109-1126. https://doi.org/10.1080/1369118X.2016.1207697

Enli, G. (2017). Twitter as arena for the authentic outsider: Exploring the social media campaigns of Trump and Clinton in the 2016 US presidential election. European Journal of Communication, 32(1), 50-61. https://doi.org/10.1177/0267323116682802

Fernández Crespo, M. (2014). Metodología para el análisis de las redes sociales. En: R. Cotarelo y J. A. Olmeda (Eds.), La democracia del siglo XXI. Política, medios de comunicación, internet y redes sociales (383-408). Centro de Estudios Políticos y Constitucionales.

Fletcher, R., Cornia, A. y Nielsen, R. K. (2020). How polarized are online and offline news audiences? A comparative analysis of twelve countries. The International Journal of Press/Politics, 25(2), 169-195. https://doi.org/10.1177/1940161219892768

Flowerdew, J. y Richardson, J. E. (2017). The Routledge Handbook of Critical Discourse Studies. Routledge.

Gainous, J. y Wagner, K. M. (2014). Tweeting to power: The social media revolution in American politics. Oxford University Press.

Geise, S., Panke, D. y Heck, A. (2021). Still images-moving people? How media images of protest issues and movements influence participatory intentions. The International Journal of Press/Politics, 26(1), 92-118. https://doi.org/10.1177/1940161220968534

Hallin, D. C. y Mancini, P. (2004). Comparing media systems. Three models of media and politics. Cambridge University Press.

Hancu-Budui, A., Zorio-Grima, A. y Blanco-Vega, J. (2020). Audit institutions in the European Union: Public service promotion, environmental engagement and Covid crisis communication through social media. Sustainability, 12(23), 9816. https://doi.org/10.3390/su12239816

Hanusch, F. y Hanitzsch, T. (2017). Comparing journalistic cultures across nations. Journalism Studies, 18(5), 525-535. https://doi.org/10.1080/1461670X.2017.1280229

Hermida, A. y Mellado, C. (2020). Dimensions of social media logics: Mapping forms of journalistic norms and practices on Twitter and Instagram. Digital Journalism, 8(7), 864-884. https://doi.org/10.1080/21670811.2020.1805779 
Jacobs, S. y Wonneberger, A. (2019). Dealing with increasing complexity: media orientations of communication manager in public sector organizations. International Journal of Communication, 13, 918-937.

Jungherr, A. (2016). Twitter use in election campaigns: A systematic literature review. Journal of $\begin{array}{llllll}\text { Information Technology } \quad \& \quad \text { Politics, } & 13(1), & 72-91 .\end{array}$ https://doi.org/10.1080/19331681.2015.1132401

Kreiss, D. y Mcgregor, S. C. (2018). Technology firms shape political communication: The work of Microsoft, Facebook, Twitter, and Google with campaigns during the 2016 U.S. presidential cycle. Political Communication, 35(2), 155-177. https://doi.org/10.1080/10584609.2017.1364814

Krippendorff, K. (2012). Content analysis: An introduction to its methodology. Sage.

Kruikemeier, S., van Noort, G., Vliegenthart, R. y de Vreese, C. H. (2013). Getting closer: The effects of personalized and interactive online political communication. European Journal of Communication, 28(1), 53-66. https://doi.org/10.1177/0267323112464837

Langer, A. I. y Gruber, J. B. (2021). Political agenda setting in the hybrid media system: why legacy media still matter a great deal. The International Journal of Press/Politics, 26(2), 313-340. https://doi.org/10.1177/1940161220925023

Larsson, A. O e Ihlen, Ø. (2015). Birds of a feather flock together? Party leaders on Twitter during the 2013 Norwegian elections. European Journal of Communication, 30(6), 666-681. https://doi.org/10.1177/0267323115595525

Losada Díaz, J. C., Rodríguez Fernández, L. y Paniagua Rojano, F. J. (2020). Comunicación gubernamental y emociones en la crisis del Covid-19 en España. Revista Latina de Comunicación Social, 78, 1-18. https://doi.org/10.4185/RLCS-2020-1467

Manfredi-Sánchez, J.-L., Amado-Suárez, A. y Waisbord, S. (2021). Presidential Twitter in the face of COVID-19: Between populism and pop politics. Comunicar, 29(66), 79-90. https://doi.org/10.3916/C66-2021-07

McAllister, I. (2007). The personalization of politics. En: R. J. Dalton y H. D. Klingemann (Eds.), The Oxford Handbook of Political Behaviour (571-588). Oxford University Press.

Nielsen, R. K., Fletcher, R., Newman, N., Brennen, J. S. y Howard, P. N. (2020). Navigating the 'infodemic': how people in six countries access and rate news and information about coronavirus. Reuters Institute for the Study of Journalism, University of Oxford.

Pérez-Curiel, C. y Velasco Molpeceres, A. M. (2020). Impacto del discurso político en la difusión de bulos sobre Covid-19. Influencia de la desinformación en públicos y medios. Revista Latina de Comunicación Social, 78, 86-119. https://doi.org/10.4185/RLCS-2020-1469

Rebolledo, M., Zamora-Medina, R. y Rodríguez-Virgili, J. (2017). Transparency in citizen participations tools and public information: A comparative study of the Spanish city councils' websites. El profesional de la información, 26(3), 361-369. https://doi.org/10.3145/epi.2017.may.02 
Rivas-de-Roca, R., García-Gordillo, M. y Bezunartea-Valencia, O. (2020). The far-right's influence on Twitter during the 2018 Andalusian elections: an approach through political leaders. Communication \& Society, 33(2), 227-242. https://doi.org/10.15581/003.33.2.227-242

Sampedro, V. y Martínez Avidad, M. (2018). The digital public sphere: An alternative and counterhegemonic space? The case of Spain. International Journal of Communication, 12, 23-44.

Scherpereel, J. A., Wohlgemuth, J. y Schmelzinger, M. (2016). The adoption and use of Twitter as a re-presentational tool among members of the European Parliament. European Politics and Society, 18(2), 111-127. https://doi.org/10.1080/23745118.2016.1151125

Sierra Rodríguez, J. (2020). Periodismo, comunicación institucional y transparencia: aprendizajes de la crisis sanitaria del COVID-19. Revista de Comunicación y Salud, 10(2), 569-591. https://doi.org/10.35669/rcys.2020.10(2).569-591

Smyrnaios, N. y Rebillard, F. (2019). How infomediation platforms took over the news: a longitudinal perspective. The Political Economy of Communication, 7(1), 30-50.

Stromer-Galley, J. (2014). Presidential campaigning in the Internet age. Oxford University Press.

van Dijk, T. A. (2015). Critical discourse analysis. En: D. Tannen, H. E. Hamilton y D. Schiffrin (Eds.), The Handbook of Discourse Analysis (466-477). John Wiley and Sons.

van Kessel, S. y Castelein, R. (2016). Shifting the blame. Populist politicians' use of Twitter as a tool of opposition. Journal of Contemporary European Research, 2(2), 594-614.

Wang, Y., Hao, H. y Platt, L. S. (2021). Examining risk and crisis communications of government agencies and stakeholders during early-stages of COVID-19 on Twitter. Computers in Human Behavior, 114, 106568. https://doi.org/10.1016/j.chb.2020.106568

Warren, G. W. y Lofstedt, R. (2021). COVID-19 vaccine rollout risk communication strategies in Europe: a rapid response. Journal of Risk Research, 24(3-4), 369-379. https://doi.org/10.1080/13669877.2020.1870533

\section{AUTOR/ES:}

\section{Rubén Rivas-de-Roca}

Universidad de Sevilla. Personal Investigador en Formación (PIF) del Departamento de Periodismo II de la Universidad de Sevilla. Doctorando en Comunicación (línea Periodismo) del programa interuniversitario de las universidades de Cádiz, Huelva, Málaga y Sevilla. Graduado en Periodismo (Premio Extraordinario Fin de Estudios y Premio Nacional Fin de Carrera 2014-2015) y Máster Universitario en Estudios Europeos (Premio Extraordinario Fin de Estudios) por la Universidad de Sevilla. Máster en Comunicación, Cultura, Sociedad y Política por la UNED. Ha sido investigador visitante en Universität Leipzig (Alemania), Cardiff University (Reino Unido) y Universidade da Beira Interior (Portugal). Sus líneas de investigación se centran en el estudio de la calidad periodística, la información local y la comunicación política, especialmente en lo referente a la Unión Europea.

rrivasderoca@us.es

Índice H: 3 
Orcid ID: https://orcid.org/0000-0001-5842-4533

Google Scholar: https://scholar.google.es/citations?user=x1QWEI8AAAAJ\&hl=es\#

ResearchGate: https://www.researchgate.net/profile/Ruben-Rivas-De-Roca

Scopus ID: https://www.scopus.com/authid/detail.uri?authorId=57190071012

Academia.edu: https://us.academia.edu/RubenRivas

\section{Mar García-Gordillo}

Universidad de Sevilla. Profesora Titular del Departamento de Periodismo II de la Universidad de Sevilla. Miembro del Grupo de Investigación SEJ-619 Communication \& Social Sciences (COM\&SOC). Actualmente es Directora General de Comunicación de la Universidad de Sevilla y, anteriormente, ha ejercido como Vicedecana de Prácticas y Empresas de la Facultad de Comunicación y como Directora del Secretariado de Prácticas en Empresas y Empleo de la Universidad de Sevilla. Actualmente imparte docencia en el Máster de Comunicación Institucional y Política y es parte del claustro de profesores del Doctorado Interuniversitario en Comunicación. Sus líneas de investigación se centran en el estudio de la calidad periodística, la comunicación política internacional y europea, la información local y los nuevos medios digitales.

marggordillo@us.es

Índice H: 12

Orcid ID: https://orcid.org/0000-0002-9367-0366

Google Scholar: https://scholar.google.es/citations?user=kLc-cAQAAAAJ\&hl=es

ResearchGate: https://www.researchgate.net/profile/Mar-Garcia-Gordillo

Scopus ID: https://www.scopus.com/authid/detail.uri?authorId=55578832900

Academia.edu: https://us.academia.edu/MarGarc\%C3\%ADaGordillo

\section{José Luis Rojas-Torrijos}

Universidad de Sevilla. Profesor Titular del Departamento de Periodismo II de la Universidad de Sevilla y miembro del grupo de investigación Communication \& Social Sciences (COM\&SOC). También es profesor en varios másteres como Innovación en Periodismo de la Universidad Miguel Hernández de Elche o Periodismo Deportivo de la Universitat Pompeu Fabra. Ponente y director de congresos y seminarios relacionados con el periodismo especializado. Su línea de investigación está centrada en el periodismo deportivo y en los libros de estilo. Entre otras, ha publicada las monografías Libros de estilo y periodismo global en español (Tirant lo Blanch, 2011), Periodismo deportivo de calidad (Fragua, 2011) y Alto y Claro. Guía de pronunciación para la cobertura de grandes eventos deportivos internacionales (Visión Libros, 2013).

jlrojas@us.es

Índice H: 16

Orcid ID: https://orcid.org/0000-0002-7390-9843

Google Scholar: https://scholar.google.es/citations?user=Tw9ceHgAAAAJ

ResearchGate: https://www.researchgate.net/profile/Jose-Torrijos-2

Scopus ID: https://www.scopus.com/authid/detail.uri?authorId=56520408600

Academia.edu: https://us.academia.edu/Jos\%C3\%A9LuisRojasTorrijos 